\title{
A New Fault Identification Method for HVDC Transmission Line
}

\author{
Sherin Tom ${ }^{1}$, Jaimol Thomas ${ }^{2}$ \\ ${ }^{1,2}$ Saintgits College of Engineering, Kottayam, Kerala, India
}

\begin{abstract}
This paper presents a transient based fault identification for High Voltage Direct Current (HVDC) system. Characteristics of the HVDC system during internal and external fault are studied. Variation of transient energy and the relation between various parameters of the line are analyzed during each fault. Based on that the transient method is developed. Transient energy can be obtained by measuring the voltage and current at the two terminals of the line. Identification of internal fault and external fault can be done correctly and quickly from the calculated value of transient energy. The transient current can be analyzed to find out the type of internal and external fault. The test system is modeled in MATLAB - SIMULINK package based on CIGRE HVDC benchmark system.
\end{abstract}

Keywords: HVDC transmission, Protection, Fault Identification, Transmission line

\section{Introduction}

High Voltage Direct Current Technology is a most attractive transmission technology when power has to be transmitted over long distances. In last half century, its application has widely increased. A total of around 70000MW of transmission capacity is transmitted around the world through 95 HVDC projects. Due to the burgeoning demand for electrical power in one area and concentration of electrical generation in another area, a number of high capacity long distance HVDC systems are planned where bulk power from one region to another region is being transmitted.

The fault taking place on HVDC transmission lines may cause the instability of the power system and lead to a large economic loss. Quickly identifying the faults can prevent the destruction of power system stability [1]. Traveling wave based methods are widely used for the detection of faults in HVDC system. But it has disadvantage such as it is easily affected by noise, difficulty in accurate detection of wavehead, requirement of complex and expensive equipments, cannot be implemented automatically etc. $[2]$.

A protection scheme based on the characteristics of low frequency differential transient energy is proposed for Ultra High Voltage Direct Current (UHVDC) systems [3],[4]. The effect of distributed parameters cannot be ignored since modern HVDC system is meant for long distance [11]-[14]. A new fault identification and location scheme is proposed in this paper. The test system is modeled in MATLAB based on CIGRE HVDC benchmark system.

\section{Protection Method}

In Figure. 1 the main structure diagram of the typical HVDC transmission system is shown. Protection devices are installed at points $\mathrm{A}$ at the rectifier $\mathrm{DC}$ side and $\mathrm{B}$ at the inverter $\mathrm{DC}$ side. $I_{A}$ and $I_{B}$ are DC currents, $V_{A}$ and $V_{B}$ are DC voltages at $\mathrm{A}$ and $\mathrm{B}$ respectively. The positive directions of currents and voltages are defined in the diagram.

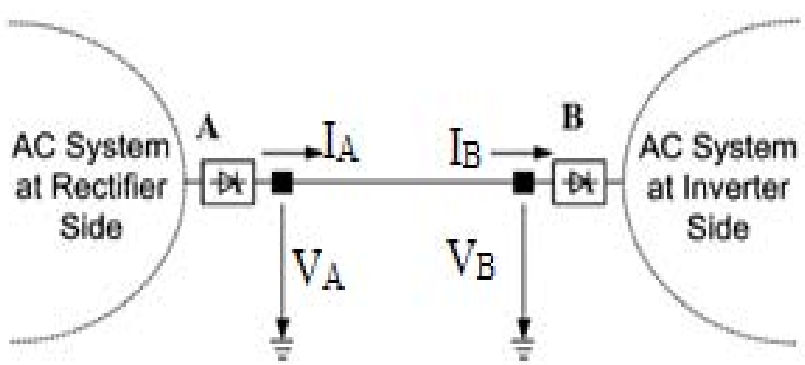

Figure 1: Structural diagram of HVDC system.

The energy at the two points is given by,

$$
\left.\begin{array}{c}
E_{A}=\int_{t_{1}}^{T_{2}} P_{A}(t) \\
E_{B}=\int_{t_{1}}^{t_{2}} P_{B}(t) d t
\end{array}\right\}
$$

The increment of the transient energy during any disturbance is given by,

$$
\left.\begin{array}{l}
\Delta E_{A}=\int_{t_{1}}^{t_{2}} \Delta P_{A}(t) d t \\
\Delta E_{B}=\int_{t_{1}}^{t_{2}} \Delta P_{B}(t) d t
\end{array}\right\}
$$

Where $P_{A}(t)$ and $P_{B}(t)$ are instantaneous power and $\Delta P_{A}(t)$ and $\Delta \mathrm{P}_{\mathrm{B}}(\mathrm{t})$ are their increments

Thus, the increment of transient energy in the dc line is

$$
\Delta E=\Delta E_{A}-\Delta E_{B}
$$

At steady state conditions,

$\Delta E_{A}=\Delta E_{B}=0$

Then,

$\Delta E=0$

When a fault occurs difference in transient energy will no longer be zero. The value of $\Delta \mathrm{E}$ will depend on the type of the fault. 


\section{International Journal of Science and Research (IJSR) \\ ISSN (Online): 2319-7064}

Index Copernicus Value (2013): 6.14 | Impact Factor (2014): 5.611

\subsection{External Fault}

The lumped parameter model of dc transmission line is shown in Figure 2. Here leakage conductance is neglected

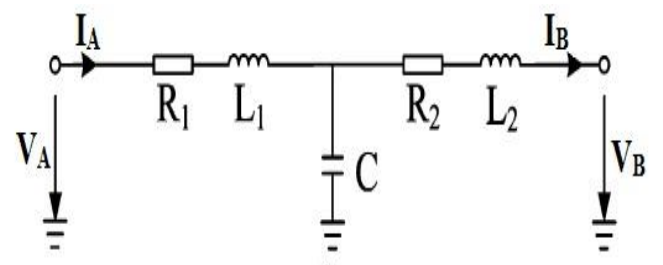

Figure 2: Lumped Parameter Model

The increment of voltage and current caused by the distributed parameters of the transmission line can be described as follows

$$
\begin{gathered}
v_{L}=R_{1} i_{A}+R_{2} i_{B}+L_{1} \frac{d i_{A}}{d t}+L_{2} \frac{d i_{B}}{d t} \\
i_{C}=C \frac{d v_{C}}{d t}
\end{gathered}
$$

Where,

$$
v_{L}=v_{A}-v_{B}
$$

$v_{L^{-}}$voltage drop in dc overhead line, $i_{C^{-}}$charging current by the equivalent shunt capacitance in the dc overhead line, $\mathrm{R}_{1}, \mathrm{R}_{2^{-}}$resistance of the dc overhead line, $\mathrm{L}_{1}, \mathrm{~L}_{2^{-}}$selfinductance of the $\mathrm{dc}$ overhead line, $\mathrm{C}$ - line-to-ground capacitance of the dc overhead line, $\mathrm{v}_{\mathrm{C}}$-capacitor voltage by equivalent shunt capacitance.

The series inductance of dc transmission line has an effect on the protective relay during the external fault at the inverter side. It is shown in Figure 3.

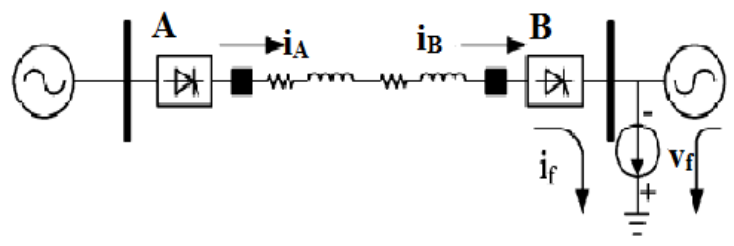

Figure 3: Effect of series inductance

The equivalent system impedance varies with fault $\mathrm{F}_{1}$ and becomes lesser than the value at normal operation. Therefore, a rapid drop in voltage occurs at two ends of the dc transmission line.

A superimposed fault current $i_{\mathrm{f}}$ can be seen in Figure 3. Now the transient currents under fault $\mathrm{F}_{1}$ at two ends of the dc transmission line can be obtained as follows

$$
\left.\begin{array}{l}
i_{A}^{\prime}=i_{A}+i_{f} \\
i_{B}^{\prime}=i_{B}+i_{f}
\end{array}\right\}
$$

Substitute (6) in (4), then

$$
v_{L}=R_{1} i_{A}+R_{2} i_{B}+\left(R_{1}+R_{2}\right) i_{f}+L_{1} \frac{d i_{A}^{f}}{d x}+L_{2} \frac{d i_{B}^{f}}{d x}
$$

And

$$
v_{A}^{b}-v_{B}^{b}=v_{L}
$$

Before $\mathrm{F}_{1}$, there is

$$
v_{A}-v_{B}=R_{1} i_{A}+R_{2} i_{B}
$$

It means

$\Delta v_{A}-\Delta v_{B}=\left(R_{1}+R_{2}\right) i_{f}+L_{1} \frac{d i_{A}^{w}}{d t}+L_{2} \frac{d i_{B}^{p}}{d x}$

So there are,

$$
\left.\begin{array}{c}
\Delta v_{A}<0 \text { and } \Delta v_{B}<0 \\
\left|\Delta v_{A}\right|<\left|\Delta v_{B}\right|
\end{array}\right\}
$$

Shunt capacitance of the dc transmission line also has an effect on its protection. There is always shunt capacitance between the overhead dc line and ground during normal operating conditions. Effect of shunt capacitance during an external fault is shown in Figure 4.

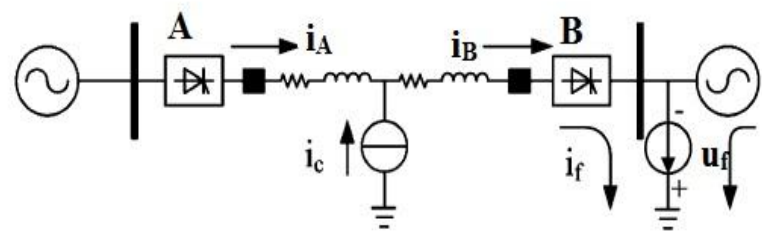

Figure 4: Effect of shunt capacitance

With the fault $\mathrm{F}_{1}$ capacitance current is discharged from the shunt capacitance to the dc line. Discharging current of the equivalent capacitor under transient state condition is substituted by an equivalent current source and is shown in Figure 4.

The equivalent discharge current of the dc line is given in (5). Under the fault $F_{1}$, the transient currents in the dc lines are,

$$
\left.\begin{array}{l}
i_{A}^{\prime}=i_{A}+i_{f}-\frac{1}{2} i_{C} \\
i_{B}^{\prime}=i_{B}+i_{f}-\frac{1}{2} i_{C}
\end{array}\right\}
$$

Increments in two transient currents are,

$$
\left.\begin{array}{l}
\Delta i_{A}=i_{f}-\frac{1}{2} i_{C} \\
\Delta i_{B}=i_{f}+\frac{1}{2} i_{C}
\end{array}\right\}
$$

It is clear that $i_{f}>i_{C}$, so from (9) and (10) there is

$$
\begin{gathered}
\Delta i_{A}>0 \text { and } \Delta i_{B}>0 \\
\left|\Delta i_{A}\right|<\left|\Delta i_{B}\right|
\end{gathered}
$$

Now the increment in power is given by,

$$
\begin{aligned}
& \Delta P_{A}=\Delta v_{A} \Delta i_{A} \\
& \Delta P_{B}=\Delta v_{B} \Delta i_{B}
\end{aligned}
$$

Substituting (8) and (11) in (12) gives

$$
\Delta P_{A}<0 \text { and } \Delta P_{B}<0
$$

Therefore $\quad\left\lfloor E_{A}|<| \Delta E_{B} \mid\right.$

$$
\left|\Delta P_{A}<\right| \Delta P_{B} \mid
$$

Then there is,

$$
\Delta E>0
$$




\section{International Journal of Science and Research (IJSR) \\ ISSN (Online): 2319-7064}

Index Copernicus Value (2013): 6.14 | Impact Factor (2014): 5.611

A similar conclusion can be obtained by analyzing the ac fault at the rectifier side based on the aforementioned procedures. External fault includes ac fault at the rectifier as well as inverter side. From the above analysis we can conclude that the difference of transient energy between two ends of the dc line is positive under external faults.

\subsection{Internal fault}

With the internal fault, the voltages at two ends of the dc line drop sharply. Figure 5 shows the superimposed circuit of the HVDC transmission system. $v_{\mathrm{f}}$ and $\mathrm{i}_{\mathrm{f}}$ are the additional fault voltage source and the additional fault current respectively. Therefore it is clear that in this condition, the current $i_{A}$ always ascends while $\hat{i}_{B}$ descends.

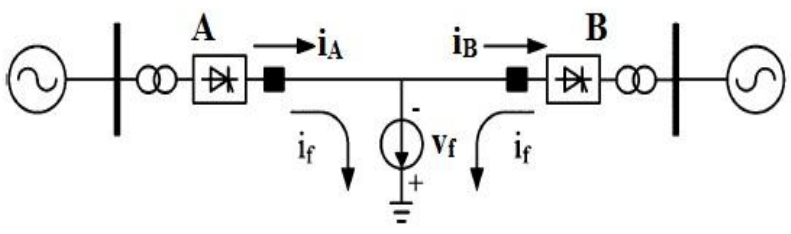

Figure 5: Internal fault

The increment of transient voltage and current will be as follows

$$
\begin{aligned}
& \Delta v_{A}<0 \\
& \Delta v_{B}<0 \\
& \Delta i_{A}>0 \\
& \Delta i_{B}<0
\end{aligned}
$$

Substituting these in (12), we get

$\Delta E_{A}<0$

$\Delta E_{B}<0$

On substituting these relations in (3) it is obvious that

$\Delta E<0$

It can be concluded as the difference of transient energy between two ends of the dc line is negative under internal faults.

\section{Identification of Type of External Fault}

External fault in HVDC system is either at the rectifier stations or at the inverter station. The value of current at the point $\mathrm{A}$ and $\mathrm{B}$ can be effectively used to identify external fault. The nominal value of $I_{A}$ and $I_{B}$ is $1 \mathrm{pu}$. Whenever fault occurs, this value changes. If the value of $I_{A}$ and $I_{B}$ are greater than the nominal value, fault will be at inverter side. If the value of $I_{A}$ and $I_{B}$ are less than the nominal value, fault will be at rectifier side.

\section{Identification of Type of Internal Fault}

The fault that occurs in an HVDC line are mainly of two types. These faults can be identified easily by analyzing the current data. Current at the two end of the dc transmission line $I_{A}$ and $I_{B}$ are different in each type of fault. Two types of faults are described below.

\section{Open Circuit}

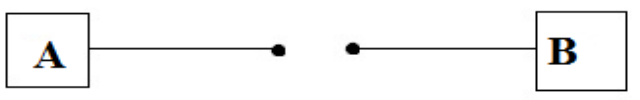

Figure 6: Open circuit fault

Figure 6 shows the open circuit fault. Here the line breaks and an open circuit fault occurs. Both current $I_{A}$ and $I_{B}$ will be equal to zero.

\section{Pole to ground fault}

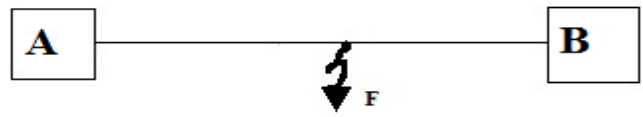

Figure 7: Pole to ground fault

This is the commonly occurring fault in de transmission line. The pole to ground fault. In this fault the value of currents $I_{A}$ and $I_{B}$ are not equal to zero. The value of $I_{A}$ will be greater than $I_{B}$

\section{MATLAB model of CIGRE HVDC benchmark system}

Modeling of HVDC system is done in MATLAB based on first CIGRE HVDC benchmark system. The system is a mono-polar 500-kV, 1000-MW HVDC link with 12-pulse converters on rectifier and inverter sides. It is connected to weak ac systems. Damped filters and capacitive reactive compensation are also provided on both sides. Total length of the transmission line is $2000 \mathrm{~km}$ [6]. System frequency is 50 $\mathrm{Hz}$. AC filters are added to absorb the harmonics generated by the converter as well as to supply reactive power to the converter. MATLAB/SIMULINK model of HVDC system is shown in Figure 8.

\section{Results}

\subsection{Identification of internal and external fault}

According to the proposed method, transient energy is used to identify internal and external faults. After modeling the CIGRE system in MATLAB, simulation is done for both external and internal faults. External fault applied is three phase fault and internal fault is pole to ground fault. At a time one of the fault is activated. Fault starts at $0.7 \mathrm{~s}$.

The transient energy during an external fault (rectifier or inverter) is shown in Figure 9. From the figure it is clear that the transient energy is positive when the fault starts at $0.7 \mathrm{~s}$. 


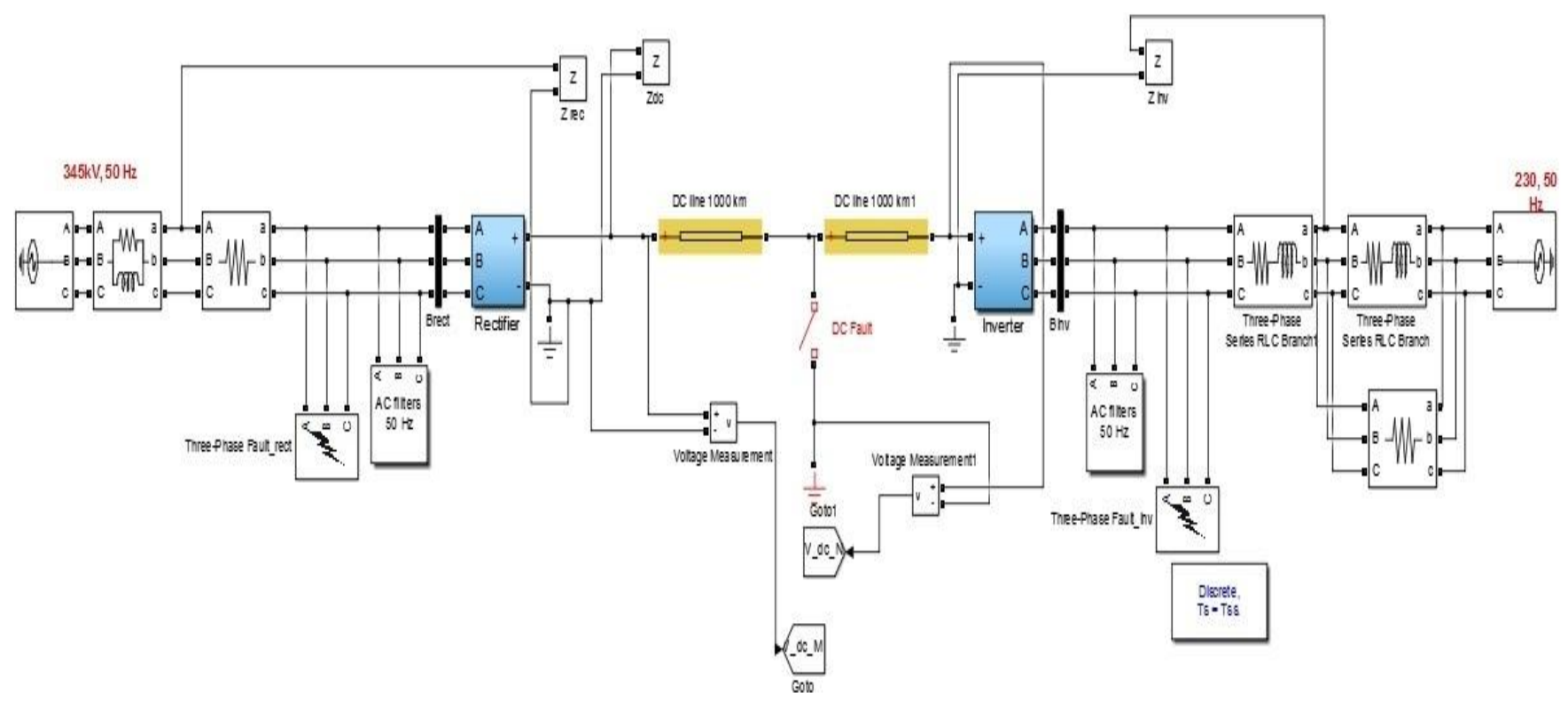

HVOC 12-pulse Transmission System 1000 MW (500kV-2kA)

Figure 8: MATLAB model of CIGRE system

Therefore transient energy can be effectively used to identify external faults.

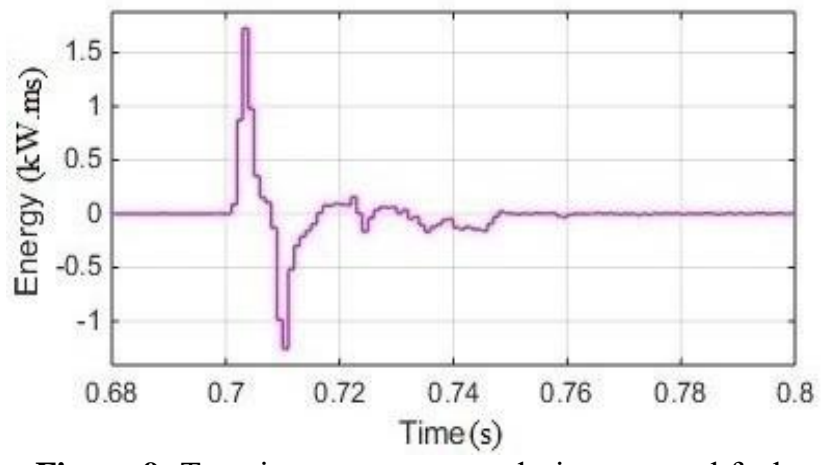

Figure 9: Transient energy curve during external fault

Transient energy during an internal fault is shown below in Figure 10. According to the proposed method transient energy should be negative during an internal fault. In the figure we can see that transient energy is negative.

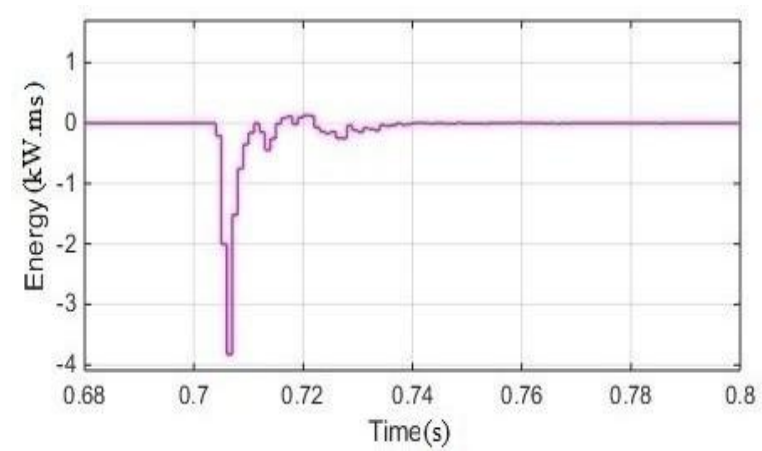

Figure 10: Transient energy during internal fault

Therefore it can be concluded that the new method identifies internal and external faults correctly and quickly.

\subsection{Identification of type of external fault}

Type of external fault is identified from the value of DC currents $I_{A}$ and $I_{B}$ during that fault. The current response of internal fault is shown below in Figure 11.

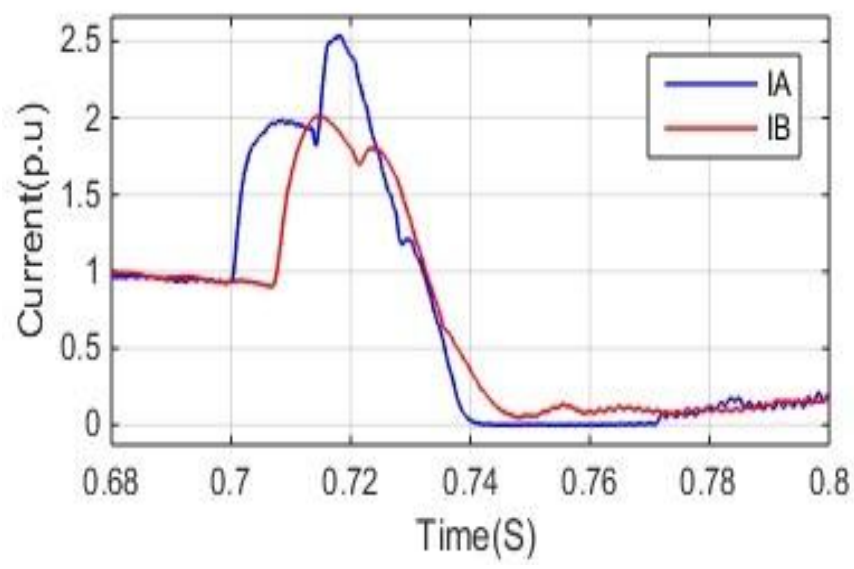

Figure 11: Current response during inverter fault

From the figure it is clear that, at the occurrence of fault both the current increases from their nominal value. It becomes greater than $1 \mathrm{pu}$.

Current response during rectifier fault is shown in Figure 12. For a rectifier fault the DC currents $I_{A}$ and $I_{B}$ at points A and $\mathrm{B}$ should be less than the nominal value $1 \mathrm{pu}$. 


\section{International Journal of Science and Research (IJSR)

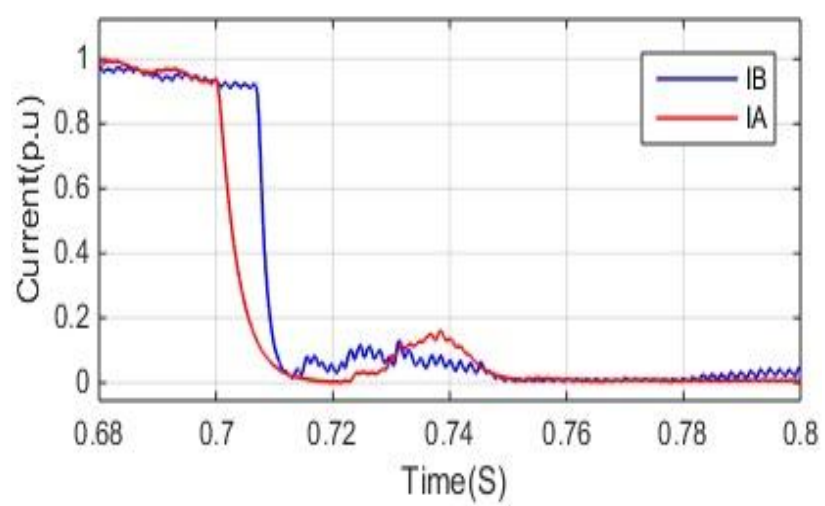

Figure 12: Current response during rectifier fault

From Figure 12 it is clear that when a fault occurs at the rectifier side both the current decline from their nominal value. They become less than $1 \mathrm{pu}$ at the occurrence of rectifier fault.

Value of $I_{A}$ and $I_{B}$ is shown in Table 1.

Table 1: Type of external fault

\begin{tabular}{|c|c|c|}
\hline$I_{A}(\mathrm{pu})$ & $I_{B}(\mathrm{pu})$ & Fault \\
\hline 0.0018 & 0.8004 & Rectifier fault \\
\hline 1.936 & 1.033 & Inverter fault \\
\hline
\end{tabular}

From Table 1 it is clear that during rectifier fault value of $I_{A}$ and $I_{B}$ are less than $1 \mathrm{pu}$ and during inverter fault is is greater than $1 \mathrm{pu}$. So the new method identifies the type of external fault accurately.

\subsection{Identification of type of internal fault}

Type of internal fault is also found out from the value of $I_{A}$ and $I_{B}$ during that fault. It is shown in Table 2 .

Table 2: Type of internal fault

\begin{tabular}{|c|c|c|}
\hline$I_{A}(\mathrm{pu})$ & $I_{B}(\mathrm{pu})$ & Fault \\
\hline 0 & 0 & Open circuit \\
\hline$\sim=0$ and $>I_{B}$ & $\sim=0$ & Pole to ground fault \\
\hline
\end{tabular}

The values of $I_{A}$ and $I_{B}$ are different in each of the fault. It means there is a particular condition of $I_{A}$ and $I_{B}$ is there for both the internal faults. These condition are checked when an internal fault occurs and whenever a condition satisfies, corresponding fault will be the output. Thus the proposed method identifies the type of internal fault correctly.

\section{Conclusion}

A new method for fault identification, based on transients is proposed for HVDC transmission lines. This method is found to be better than the commonly used travelling wave methods. Test system is modeled in MATLAB based on CIGRE HVDC benchmark system. All the fault conditions were simulated and the proposed method is found to be accurate. The proposed method is simple, reliable and fast.

\section{References}

[1] Zheng-You He, Xiao-Peng Li, Sheng Lin, Jian-Wei Yang and Rui-Kun Mai, "Natural frequency based line fault location in HVDC lines," IEEE transactions on power delivery, Vol. 29, NO. 2, APRIL 2014

[2] L. de Andrade, and T. Ponce de Leão, "Travelling Wave Based Fault Location Analysis for Transmission Lines," EPJ Web of Conferences 33, 04005 (2012), DOI: $10.1051 /$ epjconf/20123304005, Owned by the authors, published by EDP Sciences, 2012

[3] K. K. Li, C. Fan, W. L. Chan, and W. Y. Yu, "Study of protection scheme for transmission line based on wavelet transient energy," Int. J.

[4] X. L. Liu, A. H. Osman, and O. P. Malik, "Real-time implementation of a hybrid protection scheme for bipolar HVDC line using FPGA," IEEE Trans. Power Del., vol. 26, no. 1, pp. 101-108, Jan. 2011.

[5] G.WANG, J. B. LUO, H. F. LI, and Z. K LI, "Transient energy protection for $\square 800 \mathrm{kv}$ uhvdc transmission lines," (in chinese) Autom. Elect. Power Syst., vol. 34, no. 1, pp. 28-31, Jan. 2010.

[6] M. O. Faruque, Y. Zhang, and V. Dinavahi, "Detailed modeling of CIGRE HVDC benchmark system using PSCAD/EMTDC and PSB/ SIMULINK," IEEE Trans. Power Del., vol. 21, no. 1, pp. 378-387, Jan. 2006.

[7] J. O'Reilly, A. R. Wood, and C. M. Osauskas, "Frequency domain based control design for an $\mathrm{HVdc}$ converter connected to a weak AC network," IEEE Trans. Power Del., vol. 18, no. 3, pp. 1028-1033, Jul. 2003.

[8] P. Anderson and P. Anderson, Power System Protection. New York: McGraw-Hill, Dec. 1998.

[9] P. F. Gale, P. V. Taylor, P. Naidoo, C. Hitchin, and D. Clowes, "Travelling wave fault locator experience on Eskom's transmission network," in Proc. 7th Int. Conf. Develop. Power Syst. Protect., 2001, vol. 4, no. 479, pp. 327-330.

[10] X. L. Liu, A. H. Osman, and O. P. Malik, "Hybrid traveling wave/ boundary protection for monopolar HVDC line," IEEE Trans. Power Del., vol. 24, no. 2, pp. 569-578, Apr. 2009.

[11] Elect. Power Energy Syst., vol. 28, pp. 459-470, Feb. 2006. H. Takeda, H. Ayakawa, M. Tsumenaga, and M. Sanpei, "New protection method for HVDC lines including cables," IEEE Trans. Power Del., vol. 10, no. 4, pp. 2035-2039, Oct. 1995.

[12] B. Zhou and J. M. Zhao, "Steady-state stability analysis of systems HVDC considering capacitance of DC line," (in Chinese) J. North China Elect. Power Univ., pp. 4663, 1985.

[13] B. Wang, X. Z. Dong, Z. Q. Bo, and A. Perks, "RTDS environment development of ultra-high-voltage power system and relay protection test," IEEE Trans. Power Del., vol. 23, no. 2, pp. 618-623, Apr. 2008.

[14] B. Wang, X. Z. Dong, Z. Q. Bo, and A. Klimek, "Residual compensation for ground impedance relay with applications in UHV transmission lines," IEEE Trans. Power Del., vol. 24, no. 3, pp. 1072-1078, Jul. 2009.

[15] J. L. Stewart, Circuit Analysis of Transmission Lines. New York: Wiley, 1958.

[16] M. Szechtman, T. Wess, and C. V. Thio, "First benchmark model for HVDC control studies," Electra, vol. 135, no. 4, pp. 54-73, April 1991. 


\section{International Journal of Science and Research (IJSR) \\ ISSN (Online): 2319-7064}

Index Copernicus Value (2013): 6.14 | Impact Factor (2014): 5.611

\section{Author Profile}

Sherin Tom is pursuing M. Tech in power systems at Saintgits College of Engineering. She completed her B. Tech degree in Electrical and Electronics Engineering from Saintgits College of Engineering in 2012. Her area of interest are HVDC system, Generation, Transmission and Distribution.

Jaimol Thomas received doctoral degree in renewable energy sources in 2012 and M. Tech degree in 1986 from National Institute of Technology, Kozhikode. She completed her UG degree from TKM institute of Technology and science in the year 1983. Her area of interest are energy economics and power quality. 